\title{
Acute Pontine Infarct Adjoining a Preexisting Radiation-Induced Vascular Malformation 25 Years after Cranial Radiation
}

\author{
Kyu-On Jung \\ Seung-Jae Lee \\ Department of Neurology, \\ Soonchunhyang University \\ Bucheon Hospital, \\ Bucheon, Korea
}

Received November 19, 2018

Revised December 17, 2018

Accepted December 17, 2018

\section{Correspondence}

Seung-Jae Lee, MD, $\mathrm{PhD}$

Department of Neurology,

Soonchunhyang University

Bucheon Hospital,

170 Jomaru-ro, Bucheon 14584, Korea

Tel +82-32-621-6548

Fax +82-32-621-6950

E-mailnneurosj@catholic.ac.kr
Dear Editor,

A 38-year-old female patient presented with sudden-onset right hemibody hypoesthesia and paresthesia. She underwent a removal operation and radiation therapy (total radiation dose: $59.4 \mathrm{~Gy}$ ) for a right facial nerve schwannoma at the age of 13 years. A calcified radiation-induced vascular malformation (RIVM) in the pons was first seen incidentally in brain MRI performed at an age of 33 years. However, she had no vascular risk factors.

Brain MRI performed 15 hours after stroke symptom onset showed an acute lacune-like infarct involving the left medial lemniscus in the pons. It was located just left of and posterior to the preexisting RIVM, which had combined features of cavernoma (a dense hemosiderin deposit with calcification), venous malformation (dilated draining vein), and capillary telangiectasia (clustered dilated capillaries irregularly intervening in brain parenchyma) (Fig. 1). ${ }^{1}$ Magnetic resonance angiography did not show any steno-occlusion in head or neck vessels. There was no abnormality in echocardiography, 24-hour Holter monitoring, or laboratory studies (serum glucose, lipid profiles, homocysteine, and thrombophilia). She was treated with oral aspirin $(100 \mathrm{mg} /$ day $)$ and atorvastatin $(40 \mathrm{mg} /$ day $)$, and the symptom disappeared completely within 6 months.

Radiation vasculopathy causes different types of cerebral vascular lesions including largeartery diseases, lacunar lesions, vascular malformations, and hemorrhage. ${ }^{2}$ Although many studies have found multiple lesions or the recurrence of a single type of radiation vasculopathy, ${ }^{3,4}$ there have been few case reports of multiple different types of radiation vasculopathies occurring in a patient. ${ }^{5}$

RIVM can reportedly complicate symptomatic hemorrhage within lesions. ${ }^{6}$ However, an acute cerebral infarct associated with RIVM has not been reported previously. It is therefore not evident why an acute small infarct occurred near the RIVM in our patient. One possible explanation is that it was a delayed radiation vasculopathy like an RIVM. However, the adjacent nature of the two lesions raises the possibility that the preexisting RIVM affected the occurrence of stroke. Moreover, the RIVM apparently involved the path of the left paramedian branch from the basilar artery supplying the infarct area (left leminiscus). It can therefore be speculated that radiation-induced transformation of the local network of small vessels altered the regional hemodynamics around left lemniscus, contributing to the formation of an infarction. Indeed, slow flow within a cavernoma has been reported previously. ${ }^{1,7} \mathrm{~A}$ dilated vein and parenchymal capillaries together with dystrophic calcification can reflect abnormal flow dynamics associated with the lesion. ${ }^{78}$ However, this is speculative, and no further study (e.g., pathology, catheter angiography, or vessel-wall MRI) was performed. Accordingly, the present findings need to be confirmed in further case studies.

@ This is an Open Access article distributed under the terms of the Creative Commons Attribution Non-Commercial License (https://creativecommons.org/licenses/by-nc/4.0) which permits unrestricted non-commercial use, distribution, and reproduction in any medium, provided the original work is properly cited. 

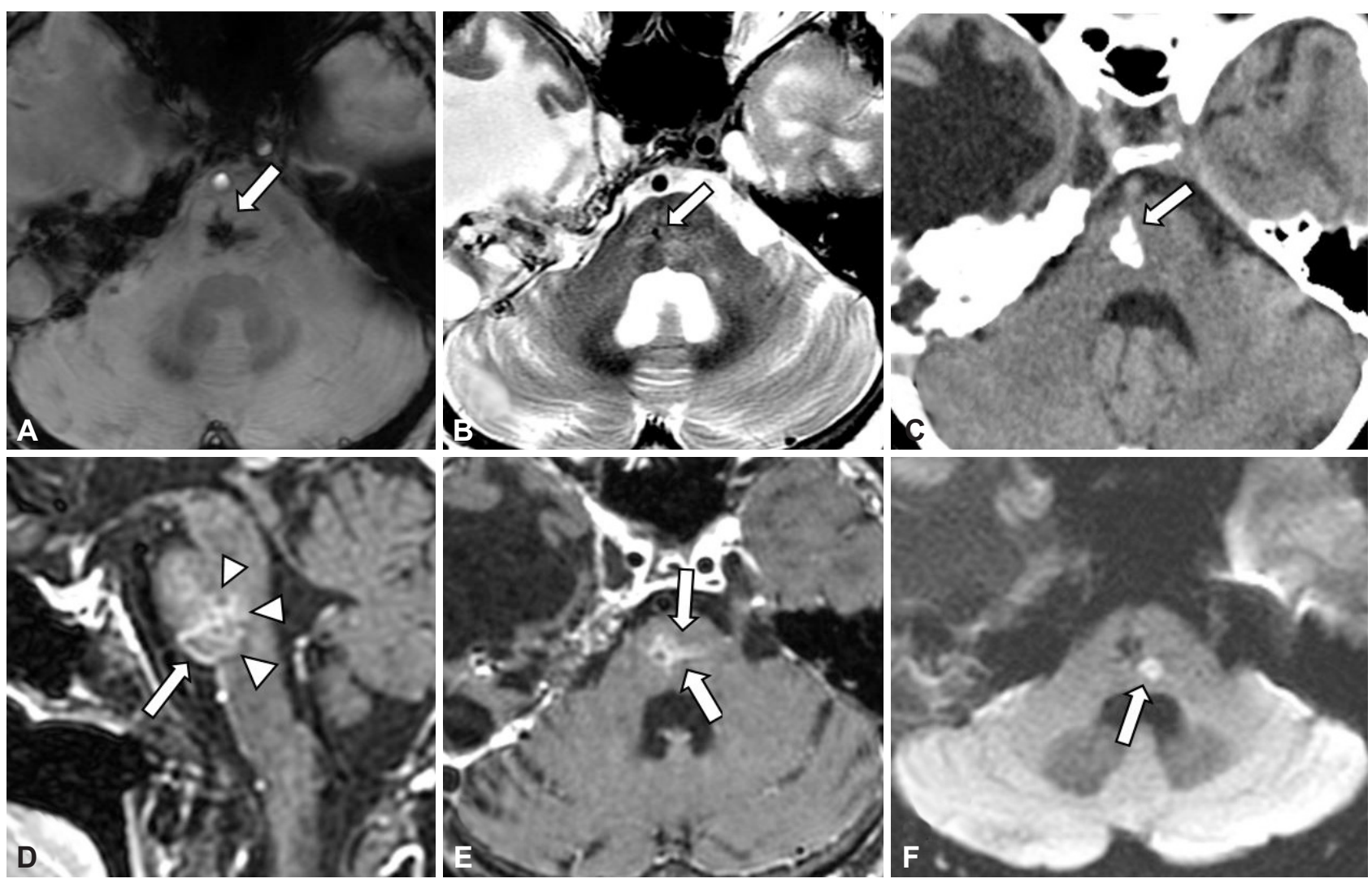

Fig. 1. Images of the radiation-induced vascular malformation and acute infarct in the pons. The vascular malformation was located principally on the right side of the mid-caudal pons, but its territory crossed the midline, involving the path of the left paramedian branch from the basilar artery. It had combined features of cavernoma, venous malformation, and capillary telangiectasia: with a dense hemosiderin deposit presenting as a hypointense lesion with a blooming effect, which appeared larger on a susceptibility-weighted image (arrow in A) than on a T2-weighted axial image (arrow in B); dystrophic calcification on a noncontrast CT axial image (arrow in C); a dilated draining vein on a contrast-enhanced T1-weighted sagittal image (arrow in D); and clustered dilated capillaries irregularly intervening in brain parenchyma on contrast-enhanced T1-weighted sagittal and axial images (arrowheads in $\mathrm{D}$ and arrows in E). An acute infarct located just left of and posterior to the preexisting vascular malformation was evident on a diffusionweighted axial image (arrow in F).

\section{Conflicts of Interest}

The authors have no potential conflicts of interest to disclose.

\section{Acknowledgements}

This study was supported by the Soonchunhyang University Research Fund.

\section{REFERENCES}

1. Frischer JM, Pipp I, Stavrou I, Trattnig S, Hainfellner JA, Knosp E. Cerebral cavernous malformations: congruency of histopathological features with the current clinical definition. J Neurol Neurosurg Psychiatry 2008;79:783-788.

2. Murphy ES, Xie H, Merchant TE, Yu JS, Chao ST, Suh JH. Review of cranial radiotherapy-induced vasculopathy. J Neurooncol 2015;122: 421-429.

3. Campen CJ, Kranick SM, Kasner SE, Kessler SK, Zimmerman RA, Lustig R, et al. Cranial irradiation increases risk of stroke in pediatric brain tumor survivors. Stroke 2012;43:3035-3040.
4. Fouladi M, Langston J, Mulhern R, Jones D, Xiong X, Yang J, et al. Silent lacunar lesions detected by magnetic resonance imaging of children with brain tumors: a late sequela of therapy. J Clin Oncol 2000;18: 824-831.

5. Kunitaka M, Akai T, Akioka N, Tomita T, Nagai S, Kuroda S. Lacunar stroke, cavernous angioma, and fusiform aneurysm due to irradiation for pilocytic astrocytoma-a case report. J Stroke Cerebrovasc Dis 2018; 27:e165-e167.

6. Cutsforth-Gregory JK, Lanzino G, Link MJ, Brown RD Jr, Flemming KD. Characterization of radiation-induced cavernous malformations and comparison with a nonradiation cavernous malformation cohort. J Neurosurg 2015;122:1214-1222.

7. Maeder P, Gudinchet F, Meuli R, De Tribolet N. Development of a cavernous malformation of the brain. AJNR Am J Neuroradiol 1998;19: 1141-1143.

8. Sarp AF, Batki O, Gelal MF. Developmental venous anomaly with asymmetrical basal ganglia calcification: two case reports and review of the literature. Iran J Radiol 2015;12:e16753. 